\title{
Molecular and Biochemical Identification and In Vitro Susceptibility to Itraconazole of Costa Rican Clinical Isolates of the Sporothrix schenckii Complex
}

\section{Stefany Lozada-Alvarado ${ }^{1,2,4 *}$, Ingrid Salas-Campos ${ }^{1}$, Lorena Uribe-Lorío $^{3}$ and Norma T Gross ${ }^{1,2}$}

${ }^{1}$ Sección de Micología Médica, Departamento de Microbiología e Inmunología, Facultad de Microbiología, Universidad de Costa Rica, Ciudad Universitaria Rodrigo Facio, San José, Costa Rica

${ }^{2}$ Centro de Investigación en Enfermedades Tropicales (CIET), Universidad de Costa Rica, Ciudad Universitaria Rodrigo Facio, San José, Costa Rica ${ }^{3}$ Centro de Investigación en Biología Celular y Molecular (CIBCM), Universidad de Costa Rica, Ciudad Universitaria Rodrigo Facio, San José, Costa Rica

${ }^{4}$ Laboratorio Clínico y Banco de Sangre Universidad de Costa Rica (LCBSUCR),

Universidad de Costa Rica, San José, Costa Rica

*Corresponding Author: Stefany Lozada-Alvarado, Laboratorio Clínico y Banco de Sangre Universidad de Costa Rica (LCBSUCR), Universidad de Costa Rica sede Hospital del Trauma, San José, Costa Rica.
Received: September 03, 2020

Published: November 27, 2020

(C) All rights are reserved by Stefany

Lozada-Alvarado., et al.

\section{Abstract}

Globally, the most frequently isolated species of the Sporothrix schenckii complex from human clinical samples are S. schenckii, S. globosa and S. brasiliensis. Sporotrichosis is the most important subcutaneous fungal infection in Costa Rica, and, so far, the etiological agents have only been identified by microscopic observation as S. schenckii. The aim of the present study was to identify by phenotypic and genotypic characteristics the species of the Sporothrix schenckii complex in a collection of Costa Rican human clinical isolates.

Fifty-seven Costa Rican clinical isolates were analyzed and 18 sequences were deposited in the GenBank database. The isolates are part of a collection of the School of Microbiology of the University of Costa Rica. For the phenotypic characterization, temperature growth, microscopic features and carbohydrate assimilation were performed, and the susceptibility to itraconazole was studied in vitro by the CLSI M-38 microdilution method. Genotypic characterization was performed by enzymatic restriction and sequencing of the calmodulin gene. The presence of two species of S. schenckii complex, i.e. S. schenckii s. str. (53) and S. globosa (4) was demonstrated. A MIC value of less than $1 \mu \mathrm{g} / \mathrm{mL}$ was found in $84.2 \%$ of the isolates. The most accurate techniques for identification of the isolates were enzymatic restriction and sequencing of the calmodulin gen. The carbohydrate assimilation test was the least useful one. All isolates studied were sensitive to itraconazole.

Keywords: Sporothrix schenckii; Sporothrix globosa; Sporothrix sp.; Sporotrichosis; Susceptibility Testing

\section{Introduction}

Sporothrix spp., is the etiological agent of sporotrichosis, a chronic subcutaneous granulomatous disease, which has been described mainly in humans and animals such as cats and dogs. The disease is acquired by traumatic inoculation and has a worldwide distribution; being Japan, Mexico, Brazil, Uruguay, Peru and Colombia the countries that report the most cases [1]. Among isolates of Sporothrix schenckii, differences were initially established based 
Molecular and Biochemical Identification and In Vitro Susceptibility to Itraconazole of Costa Rican Clinical Isolates of the Sporothrix schenckii Complex

on macroscopic and microscopic characteristics [2,3]. Then, Marimon., et al. in 2007 [4] confirmed the existence of several species, based on the colony appearance, size and pigment of radulospores and assimilation of carbohydrates. Further, the evolution of the complex has been separated in clades that represent the species [2-4].

In Costa Rica, this infection it is considered to be the most frequent subcutaneous mycosis, followed by chromoblastomycosis and mycetoma [5]. The traditional treatment is potassium iodide; however, itraconazole was introduced as an alternative therapy because of its low toxicity and good tolerance [6]. In Costa Rica, all the isolates involved in clinical cases have been identified as S. schenckii by morphological features [7]. To our knowledge no study has been conducted on the S. schenckii species complex, thus, there is a necessity of molecular characterization of the isolates previously classified as $S$. schenckii.

\section{Aim of the Study}

The aim of the present study was to identify the species of the S. schenckii complex in a collection of Costa Rican human clinical isolates, based on their sequence of the calmodulin gene and their phenotypic characteristics such as assimilation of carbohydrates, growth at three temperatures, morphology of radulospores and itraconazole in vitro susceptibility.

\section{Materials and Methods}

\section{Clinical isolates}

Fifty-seven isolates from the Medical Mycology Collection of the School of Microbiology, University of Costa Rica, collected between 1994 and 2015, were analyzed in the present study. The reference strains used in all experiments were S. brasiliensis (CBS 120339), $S$. globosa (CBS 120340), S. mexicana (CBS 120341) and S. schenckii s. str. (CBS 938.72) [4].

\section{Growth at different temperatures}

All isolates were maintained in Sabouraud dextrose medium (peptone, dextrose, agar, $\mathrm{pH}$ 5.6). Isolates were cultured for five days; thereafter, one millimeter diameter portions of the fungal culture were inoculated onto potato dextrose agar plates (potato extract, dextrose, agar, pH 5.6) and incubated at temperatures of 25,30 and $37^{\circ} \mathrm{C}$, in duplicates. Growth diameter measurements were made on day 21 of incubation [4].

\section{Microculture}

The isolates studied were inoculated onto $1 \mathrm{~cm}^{2}$ portions of oat agar (oatmeal, agar, water, $\mathrm{pH}$ 6.0). The incubation was carried out in a humid chamber at $30^{\circ} \mathrm{C}$, in the dark for 12 days. Then, the size of 25 radulospores were measured for each isolate and the presence or absence of pigment in these spores was recorded [4].

\section{Carbohydrate assimilation}

According to the protocol described by Marimon [4], peptone water solutions were supplemented with raffinose, glucose and sucrose (Sigma-Aldrich, MO, USA), at a final concentration of $2 \%$ and $150 \mu \mathrm{L}$ were distributed in each well of a 96-well plate (Evergreen Scientific, Los Angeles, California). A spore suspension was obtained with sterile saline $(0.5 \%)$ and was counted in a Bürker chamber (Poly-Optik GmbH Blankenburg, Germany). The suspension was adjusted to a concentration between $2 \times 10^{5}$ to $2 \times 10^{6}$ Colony Forming Units (CFU)/mL. Then, $50 \mu \mathrm{L}$ of the spore suspension was added to each well, except for the negative control to which only sterile saline was added. Wells containing glucose were the growth controls. Plates were then incubated at room temperature for 5 and 10 days. The presence or absence of growth in each well was evaluated visually and recorded. All the experiments were done in triplicates.

\section{Itraconazole in vitro susceptibility}

The in vitro susceptibility to itraconazole of each of the isolates was performed for the mycelial form of the dimorphic fungi [8]. The concentrations evaluated were 0.06 - $32 \mu \mathrm{g} / \mathrm{mL}$ of itraconazole (Royal Pharm, Hangzhou, China). The minimum inhibitory concentration (MIC) was established as the lowest concentration that produced a total inhibition of growth $100 \%$ inhibition as compared to the growth control wells). In all experiments, Candida krusei ATCC 6258 and Candida parapsilosis ATCC 22019 were used as quality control strains [8].

\section{Analysis of the calmodulin gene}

DNA was extracted using the Nucleo Spin ${ }^{\circledR}$ Tissue kit (MachereyNagel, Germany), following the procedure described in the insert. To amplify the calmodulin gene, two primers were used: CL1- 5 'GA (GA) T (AT) CAA GGA GGC CTT CTC 3' (10 pmol/ $\mu \mathrm{L})$ and CL2A- 5 TTT TTG CAT CAT GAG TTG GAC 3' (10 pmoles/ $\mu \mathrm{L}$ ), with an expected product size between 600 and 800 bp [9]. Restriction analysis of the PCR product was performed as described by Rodriges., et al. 2014, using the enzyme HhaI endonuclease (Thermo Fisher Scien- 
Molecular and Biochemical Identification and In Vitro Susceptibility to Itraconazole of Costa Rican Clinical Isolates of the Sporothrix schenckii Complex

tific Inc., MA USA) [10], incubating at $37^{\circ} \mathrm{C}$ overnight. The digested products were electrophoresed on $2.5 \%(\mathrm{w} / \mathrm{v})$ agarose gels for 90 minutes at $100 \mathrm{~V}$ in the presence of GelRed ${ }^{\circledR}$ (Biotium, Inc., CA, USA) using a Gene Ruler marker of 50 pb DNA Ladder $0.1 \mu \mathrm{g} / \mu \mathrm{L}$ (Fermentas, Waltham, MA, USA). The bands were visualized with a Bio Doc-it ${ }^{\circledR} 220$ Imaging System PCR and were analyzed by an Unweighted Pair Group Method with Arithmetic Mean (UPGMA) graph. The products of PCR were sequenced using the services of Macrogen Inc (South Korea).

\section{Phylogenetic analysis}

The sequences obtained were edited using the BioEdit software and aligned with ClustalW in the MEGA7 program. The distance matrix was calculated according to Kimura [11] and the phylogenetic trees were constructed using Bayesian Inference using the MrBayes 3.2.6 program. A total of 1000 replicas were analyzed, and the percentage of bootstrap is shown in each branch of the tree.

\section{Statistical analysis}

For the analysis of the phenotypic characteristics, the measurements in the lengths of the radulospores and the percentages of growth inhibition an analysis of variance was performed using the GraphPad Prism program, version 5.00 for Windows (GraphPad Software, CA, USA).

\section{Results and Discussion}

All the isolates grew at temperatures of 25 and $30^{\circ} \mathrm{C}$. The average growth diameter at $25^{\circ} \mathrm{C}$ was $37 \mathrm{~mm}$ and at $30^{\circ} \mathrm{C}$ was 30.93 $\mathrm{mm}$. The reference strain $S$. mexicana showed the maximum average growth at 25 and $30^{\circ} \mathrm{C}, 68.25 \pm 1.50 \mathrm{~mm}$ and $60.25 \pm 2.36 \mathrm{~mm}$, respectively (Table 1 ). The statistical analysis of one-way variance showed statistically significant differences $(\mathrm{p}<0.0001)$ among the growth diameters at the different temperatures tested (Table 1).

\begin{tabular}{|l|c|c|c|c|}
\hline \multirow{2}{*}{$\begin{array}{l}\text { Number of } \\
\text { isolates }\end{array}$} & \multicolumn{4}{|c|}{ Growth diameter (mm) at $\mathbf{2 1}$ days } \\
\cline { 2 - 5 } & $\begin{array}{c}\text { Presumptive } \\
\text { ID }\end{array}$ & $\mathbf{2 5}^{\circ} \mathbf{C}$ & $\mathbf{3 0}^{\circ} \mathbf{C}$ & $\mathbf{3 7}^{\circ} \mathbf{C}$ \\
\hline 24 & SPSC & $26,25-51,50$ & $22,50-39,50$ & $2,22-4,90$ \\
\hline 33 & SPGL & $29,00-47,75$ & $16,75-46,25$ & 0 \\
\hline S. schenckii $^{a}$ & SPSC & 28.00 & 33.00 & 5.75 \\
\hline S. brasiliensis $^{a}$ & SPBR & 45.00 & 33.00 & 2.75 \\
\hline S. globosa $^{a}$ & SPGL & 40.50 & 23.75 & 0 \\
\hline S. mexicana $^{a}$ & SPMX & 68.25 & 60.25 & 0 \\
\hline
\end{tabular}

Table 1: Distribution of mycelial growth of Costa Rican clinical isolates of the Sporothrix schenckii complex, at different temperatures. SPSC: Sporothrix schenckii; SPGL: Sporothrix globosa; SPBR: Sporothrix brasiliensis; SPMX: Sporothrix mexicana.

a: Reference strains.

Under the light microscope, all isolates presented the typical Sporothrix sp. morphology: septate hyaline hyphae, sympodial conidiophores and radulospores [1] (Figure 1). All isolates showed pigmented radulospores. The reference strain of S. globosa showed strongly pigmented, globose and rounded radulospores, and the size was between $4-3 \times 3-2 \mu \mathrm{m}$, as described by Marimon [4] (Figure 1A). As to reference strain of $S$. schenckii s. str., sessile, pigmented, rounded and triangular radulospores were observed. The size of the radulospores ranged between $2-2 \times 2-1 \mu \mathrm{m}$ (Figure 1B). By means of the microculture, it was possible to determine the presence of two species among the clinical isolates studied: 93\% showed microscopic characteristics compatible with $S$. schenckii s. str., while the remaining 7\% presented characteristics of S. globosa.
The majority of the isolates (93\%) of the present study showed assimilation of sucrose and raffinose, as described for S. schenckii s. str., and 3.5\% did not assimilate any of the carbohydrates, as described for $S$. brasiliensis. It is noteworthy that with this technique the reference strains $S$. brasiliensis and S. globosa could not be correctly identified (Table 2).

All the isolates analyzed in the present study showed susceptibility to itraconazole; MIC $\leq 4 \mu \mathrm{g} / \mathrm{mL}$, according to Zhao., et al [12]. The majority of the isolates (84.2\%) had a MIC of less than $1 \mu \mathrm{g} /$ $\mathrm{mL}$. The average MIC was $0.52 \mu \mathrm{g} / \mathrm{mL}$ and the maximum was 3.00 $\mu \mathrm{g} / \mathrm{mL}$ (isolate SPSC-132). 


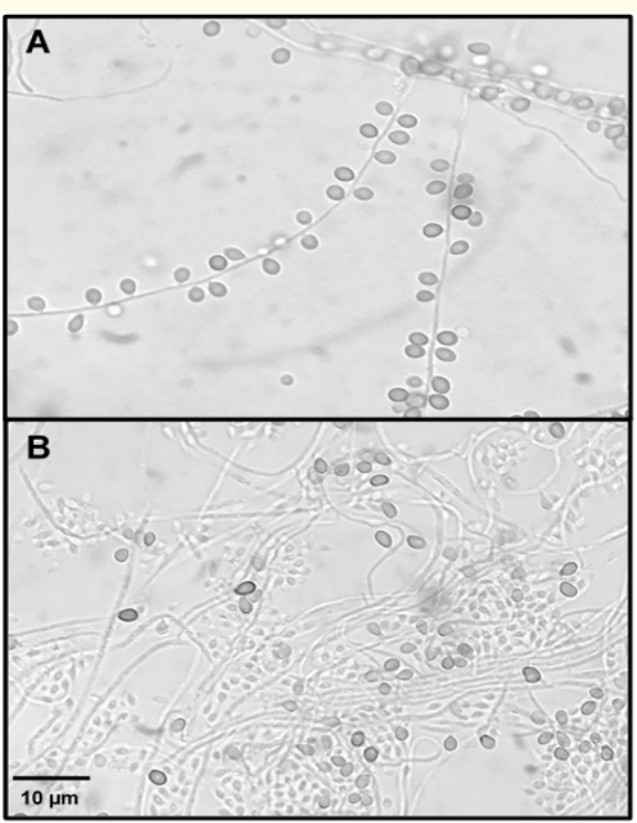

Figure 1: Microscopic view of Sporothrix species. (A) Sporothrix globosa (CBS 120340) (B) Sporothrix schenckii s. str. (CBS 938.72).

\begin{tabular}{|c|c|c|c|c|}
\hline Number of isolates & $\begin{array}{l}\text { Presump- } \\
\text { tive ID }\end{array}$ & $\begin{array}{l}\text { Glu- } \\
\text { cose }\end{array}$ & $\begin{array}{c}\text { Su- } \\
\text { crose }\end{array}$ & $\begin{array}{l}\text { Raffi- } \\
\text { nose }\end{array}$ \\
\hline 53 & SPSC & + & + & + \\
\hline 1 & SPGL & + & + & - \\
\hline 2 & SPBR & + & - & - \\
\hline 1 & $\mathrm{NI}^{\mathrm{b}}$ & + & - & + \\
\hline Sporothrix schenckiia & SPSC & + & + & + \\
\hline Sporothrix brasiliensis ${ }^{a}$ & SPSC & + & + & + \\
\hline Sporothrix globosa ${ }^{a}$ & SPSC & + & + & + \\
\hline Sporothrix mexicana ${ }^{a}$ & SPMX & + & + & + \\
\hline
\end{tabular}

Table 2: Assimilation of carbohydrates for the Costa Rican clinical isolates of the Sporothrix schenckii complex, after 10 days of incubation.

SPSC: Sporothrix schenckii; SPGL: Sporothrix globosa; SPBR: Sporothrix brasiliensis; SPMX: Sporothrix mexicana.

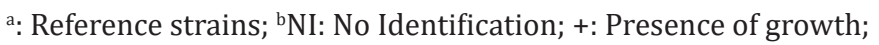
-: Absence of growth.

All the enzymatic restriction patterns coincided with those described by Rodrigues., et al [10]. The multivariate statistical analysis UPGMA, based on a matrix of presence or absence of the restriction fractions, showed similarities among these isolates. The constructed data matrix was built using the fragments 313,251 , 249, 233, 232, 215, 198, 197, 196 and 96 bp. The dendrogram (Figure 2) distributed the isolates into three groups: the first group is only composed by the reference strain of $S$. brasiliensis, the second group by 53 clinical isolates and the reference strain of $S$. schenckii s. str., and finally, the third group by four isolates and the reference strain of S. globosa.

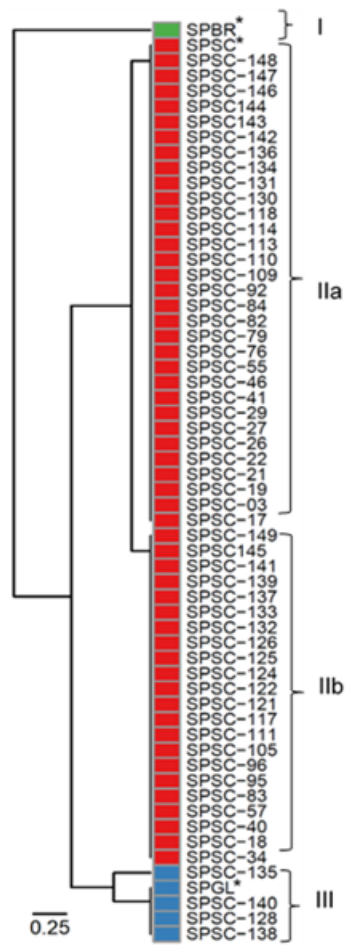

Species

Sporothrix schenckii Sporothrix qlobosa Sporothrix brasiliensis

* Reference strains

Figure 2: Clustering of the isolates according to the restriction profile of the calmodulin gene by the UPGMA analysis.

As restriction analysis of the calmodulin gene showed high homology between the groups IIa and IIb DNA, only 14 representatives from these groups were selected to sequence, in addition to four isolates in group III (species $S$. globose). All these sequences showed high similarity with sequences in the GenBank database and the percentage of similarity with type strains of the database exceeded $97 \%$. The aligned sequences presented a length of 462 bp. There were a total of 1004 positions in the final dataset. For the phylogenetic analysis, 42 sequences obtained from GenBank were included. A tree of maximum parsimony was generated with a consistency index of 0.82 and a retention index of 0.96 . The Costa Rican isolates sequences were grouped in clades II and III (Figure 3 ). The topography of the tree shows a $100 \%$ resampling (Bootstrap) for clade I, 74\% for clade II and $100 \%$ for clades III and IV. The sequences were deposited in the GenBank database, with the accession number are MH263693-MH23696 for S. globosa and MH514898-MH514911 for S. schenckii. 


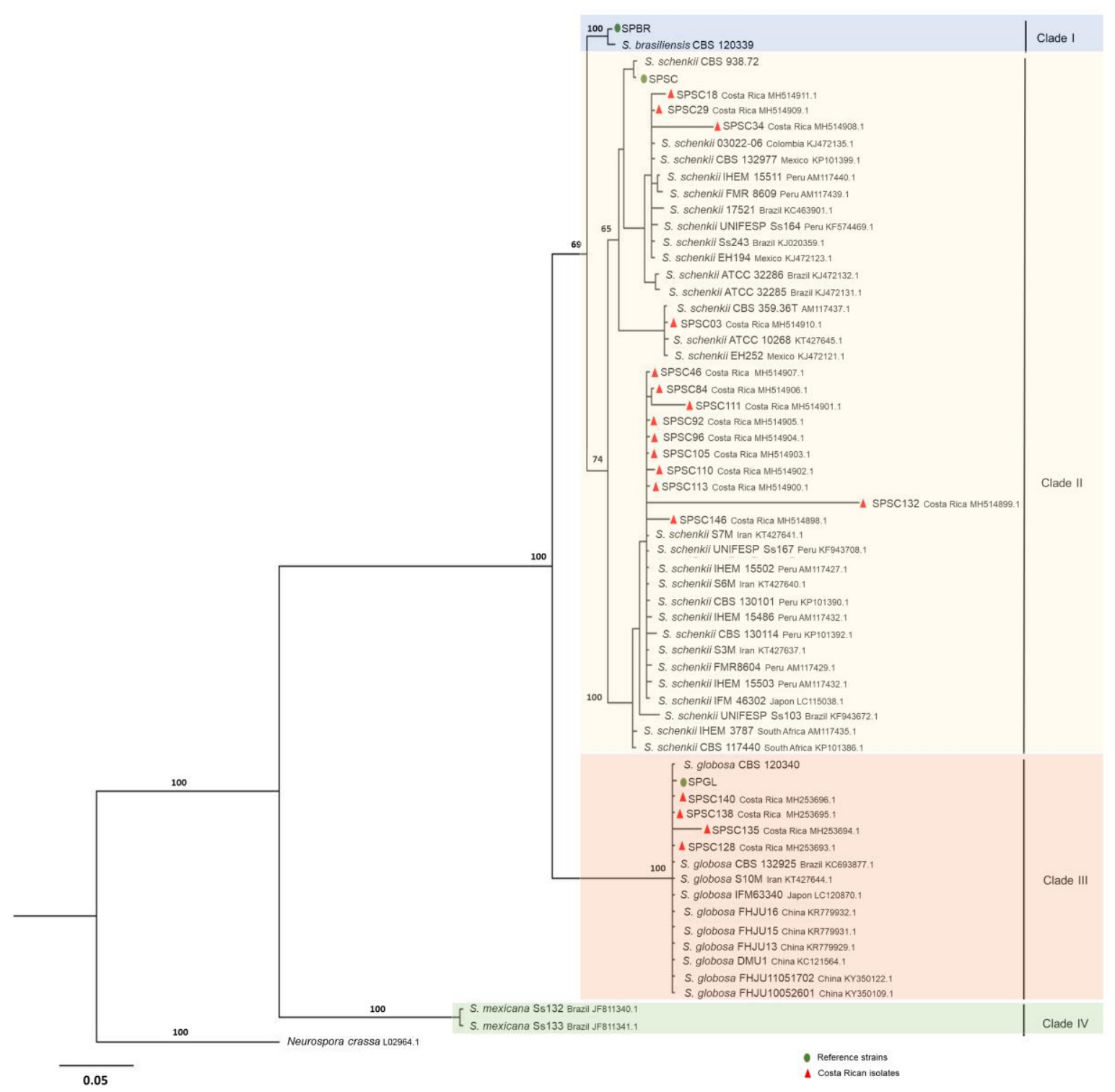

Figure 3: Phylogenetic tree of the calmodulin gene obtained by Bayesian Inference. 1000 replicas were analyzed, the percentage of bootstrap is shown in each branch of the tree. The red triangles show the Costa Rican isolates; the green circle indicate the reference

strains.

In the present study both phenotypic and genotypic approaches were carried out in order to give insights into the species of the S. schenckii complex found in Costa Rica. Isolates were collected from patients coming from the provinces of Heredia, Alajuela and Guanacaste, San Jose and Limon. This geographic distribution may show a representative data set of all the country.
It has been previously considered that all cases of human sporotrichosis in the country were caused only by S. schenckii s. str., as reported by microscopic characteristics [7]. However, with the data hereby presented it can be affirmed that two species, $S$. schenckii s. str. and S. globosa circulate in the country. The data of microscopic morphology, mycelial growth at $37^{\circ} \mathrm{C}$ and the sequence of 
Molecular and Biochemical Identification and In Vitro Susceptibility to Itraconazole of Costa Rican Clinical Isolates of the Sporothrix schenckii Complex

the calmodulin gene were considered to reach these results, as it has already been presented in previous studies in other countries $[4,13,14]$.

In regard to different temperature growth, $60 \%$ of the isolates did not show mycelial growth at $37^{\circ} \mathrm{C}$. According to Marimon., et al. [4], S. globosa was the only species that did not show mycelial growth at this temperature; accordingly, it can be considered a species found among the isolates studied. On the other hand, preliminary identification based on the growth diameter of the colony, showed no correspondence with those species identified by means of molecular biology. Considering that the new identification standard in Mycology is DNA sequencing [15] and for the genus Sporothrix is the sequencing of the calmodulin gene, it could be concluded that growth at $37^{\circ} \mathrm{C}$ is not a useful tool for identification of the species of the complex. Our results are in agreement with those shown by Camacho., et al. [13] in Venezuelan isolates.

Mycelial growth at $37^{\circ} \mathrm{C}$ has not been related to pathogenesis but the pathogenic capacity of $S$. globosa in a murine model has been demonstrated [16], but there are contradictory results with respect to the behavior of the isolates, since some S. globosa isolates have shown growth at $37^{\circ} \mathrm{C}$ as we present in this work. Therefore, more studies are required to confirm or detract the relationship that may exist between the capacity of mycelial growth at 37 ${ }^{\circ} \mathrm{C}$ and its pathogenic capacity.

The microscopic studies showed differences in the shape and size of the radulospores; the four isolates identified as $S$. globosa by sequencing, produced large ( $4-3 \times 3-2 \mu \mathrm{m})$ and globoseshaped radulospores while the 53 isolates identified as S. schenckii s. str. produced smaller ( $2-2 \times 2-1 \mu \mathrm{m})$ and round to elliptical radulospores. Therefore, the size and shape of the radulospores can be considered a good tool for the identification of the species.

With regard to the assimilation of carbohydrates, $5 \%$ of the clinical isolates studied did not assimilate sucrose or raffinose, which according to Marimon., et al. [4], would have been classified as $S$. brasiliensis. However, by sequencing of the calmodulin gene they were in fact $S$. schenckii s. str. The rest of the isolates were identified as $S$. schenckii s. str. by carbohydrate assimilation, but four of these were S. globosa. These findings are in agreement with previous studies from South America, where the isolates showed different identification by using assimilation of carbohydrates as compared to the genotypic characterization [2,13,14,17].
All the isolates of the present study were susceptible to itraconazole. The MIC values were between 1 and $3 \mu \mathrm{g} \mathrm{ml}$, and according to a recent study values between 1 and $4 \mu \mathrm{g} / \mathrm{ml}$ are considered susceptible [12]. Thus, itraconazole represents a good alternative in the treatment of sporotrichosis in this country. Although none of the isolates was resistant and no significant differences has been found between the action of the drug and the species involved [18], it could be valuable to perform susceptibility testing of the etiological agent of sporotrichosis to itraconazole, given the emergence of resistance of S. globosa to this drug [19].

The phylogenetic analysis of the gene coding for calmodulin is used for the identification of the species of the Sporothrix schenckii complex, because it has a higher percentage of variable sites (54.5\%) and of sites with parsimonious information (42.8\%), as compared to other genes such as the elongation factor or the ITS region [15,20,21]. The phylogenetic tree of the present study showed a distribution of the species in four clades statistically well supported (100\% bootstrap). Clade II grouped the Costa Rican isolates identified as $S$. schenckii s. str. These results are supported by a bootstrap percentage of $74 \%$, which makes it possible to ensure the isolates grouped in this clade belong to this species. These isolates show similarity with circulating species from South America in countries like Peru and Brazil [22]. However, some sequences showed high similarity with the sequences of Mexico, a finding that could be explained by geographical migration and the worldwide distribution of this species [23].

Geographical restriction of the Sporothrix species is probably due to their separation when continents were divided, this formation of barriers facilitated the isolation and differentiation of species according to the available hosts and the environmental conditions. It is likely that this phenomenon keeps the species restricted according to the soil and host where they originally differed [9]. Although some researchers suggest that the dispersion of the two species found worldwide, i.e., S. schenckii sensu stricto and S. globosa may be due to air dispersion [22], there is still no evidence of this phenomenon and the question is raised why only this dispersion could have two species, while the other two, i.e., S. brasiliensis and $S$. mexicana remain so restricted to a single territory.

The sequence of the isolate SPSC-03, show high similarity with the reference strain CBS 359.36T (S. schenckii) and the ATCC 10268 (S. schenckii); however, due to a lack of information about the clinical presentation and the place of isolation no comparison can be made among these strains. 
Molecular and Biochemical Identification and In Vitro Susceptibility to Itraconazole of Costa Rican Clinical Isolates of the Sporothrix schenckii Complex

Clade III corresponds to the reference strain S. globosa and the four Costa Rican isolates. This group is supported by a $100 \%$ bootstrap. According to Nath., et al. [14], clade III shows that the strains that have been described are clones from Asia, mainly from China. Accordingly, all strains show very similar sequences of the calmodulin gene. In this way, Moussa., et al. [17] show in their work that the isolates grouped in this clade has a low variability in the sequence of this gene.

In the present study, S. schenckii s. str. was the most frequently found species (93\%), a finding that is in agreement with the reported geographical prevalence [22]. Accordingly, it is also the most frequent species reported in the western part of South America, in Central and North America (89\%), Australia and Southern Africa (94\%). However, S. globosa is the most prevalent in Asia (99.3\%) and S. brasiliensis (88\%) in Southeastern Brazil. In Central America the only study available is from Guatemala, where Madrid., et al. [24] reported one isolate from S. globosa and two from S. schenckii s. str. When comparing the sequences with those of the present work, they have greater similarity to those studied in countries such as Brazil, Colombia and Peru.

Therefore, the present study is the only one in the region where the existence of circulating species and their phenotypic characterization is established, the conclusion being that there are two etiological agents of sporotrichosis in Costa Rica: S. schenckii s. str. and S. globosa.

\section{Conclusion}

There are two etiological agents of sporotrichosis in Costa Rica: S. schenckii s. str. and S. globosa.

The best techniques to identify and differentiate these species are enzymatic restriction and sequencing of the calmodulin gene, however, the microscopic morphology of the radulospores can be a useful tool when the molecular techniques are not available. As previously stated, the isolates analyzed in the present study were similar to strains from South America, maybe due to population migration and geographic proximity of the countries. It is necessary to improve the clinical diagnosis of the species involved in the pathogenesis of humans and animals. Also, it is important to investigate the epidemiological situation of the fungi in Costa Rica, its environmental presence in the soil and to establish a relationship between the climate and the increase in the number of cases.

\section{Acknowledgements}

The authors would like to thank Mr. Juan Diego Castro for helping with the maintenance of the fungal collection. This work was supported by the Vicerrectoría de Investigación, Universidad de Costa Rica [grant number B7-344].

\section{Author's Contribution}

Stefany Lozada-Alvarado performed data collection, processed the data and drafted the manuscript; Ingrid Salas-Campos, designed the proposal, processed the data and drafted the manuscript; Lorena Uribe-Lorío, designed the proposal, processed the data and drafted the manuscript; Norma T. Gross conceived and designed the proposal, processed the data, coordinated the resources and drafted the manuscript.

\section{Conflict of Interest}

The authors have declared that no competing interests exist.

\section{Bibliography}

1. Rippon JW. "Micología Médica". $3^{\text {rd }}$ edition. México DF: Nueva Editorial Interamericana (1990).

2. Ghosh A., et al. "Physiological characters of Sporothrix schenckii isolates". Mycoses 45.1-12 (2002): 449-454.

3. Dixon DM., et al. "Isolation and Characterization of Sporothrix schenckii from clinical and environmental sources associated with the largest U.S. epidemic of Sporotrichosis". Journal of Clinical Microbiology 29.6 (1991): 1106-1113.

4. Marimon R., et al. "Sporothrix brasiliensis, S. globosa, and S. mexicana, three new Sporothrix species of clinical interest". Journal of Clinical Microbiology 45.10 (2007): 3198-32060.

5. Jaramillo 0. "Esporotricosis en Costa Rica". Bol Méd Seg Soc Costa Rica 4 (1972): 27-37.

6. Kauffman CA., et al. "Infectious Diseases Society of America. Clinical practice guidelines for the management of sporotrichosis: 2007 update by the infectious Diseases Society of America". Clinical Infectious Diseases 45.10 (2007): 12551265.

7. Rodríguez J. "Aspectos clínicos, epidemiológicos y ecológicos sobre 100 casos de Esporotricosis en Costa Rica". Revista Costarricense de Ciencias Médicas 13.3-4 (1992): 29-36. 
8. Cantón Lacasa E., et al. "Métodos estandarizados por el CLSI para el estudio de la sensibilidad a los antifúngicos (documentos M27-A3, M38-A y M44-A)". Revista Iberoamericana de Micología 15a (2007): 1-17.

9. Marimon R. "Filogènia molecular i caracterització fenotípica del complex d'espècies d' Sporothrix schenckii. [Tesi doctoral]. Universitat Rovira i Virgili: Facultat de Medicina i Ciències de la Salut Departament de Ciències Mèdiques Bàsiques (2007).

10. Rodrigues AM., et al. "Genotyping species of the Sporothrix schenckii complex by PCR-RFLP of calmodulin". Diagnostic Microbiology and Infectious Disease 78.4 (2014): 383-387.

11. Kimura M. "A simple method for estimating evolutionary rates of base substitutions through comparative studies of nucleotide sequences". Journal of Molecular Evolution 16.2 (1980): 111-120.

12. Zhao MD., et al. "Morphological and physiological comparison of taxa comprising the Sporothrix schenckii complex". Journal of Zhejiang University Science B 16.11 (2015): 940-947.

13. Camacho E., et al. "Molecular epidemiology of human sporotrichosis in Venezuela reveals high frequency of Sporothrix globose". BMC Infectious Diseases (2015): 15-94.

14. Nath R., et al. "Molecular identification and phenotypic characterisation of Sporothrix globosa from clinical cases of Eastern Assam, North-east India". Indian Journal of Medical Microbiology 35.2 (2017): 269-273.

15. Balajee SA., et al. "Sequence-based identification of Aspergillus, Fusarium and mucorales species in the clinical mycology laboratory: Where are we and where should we go from here?" Journal of Clinical Microbiology 47.4 (2009): 877-884.

16. Arrillaga-Moncrieff I., et al. "Different virulence levels of the species of Sporothrix in a murine model”. Clinical Microbiology and Infection 15.7 (2009): 651-655.

17. Moussa TAA., et al. "Origin and distribution of Sporothrix globosa causing sapronoses in Asia”. Journal of Medical Microbiology 66.5 (2017): 560-569.

18. Kohler LM., et al. "In vitro susceptibilities of isolates of Sporothrix schenckii to itraconazole and terbinafine". Journal of Clinical Microbiology 42.9 (2004): 4319-4320.

19. Fischman Gompertz O., et al. "Atypical Clinical Presentation of Sporotrichosis Caused by Sporothrix globosa Resistant to Itraconazole". The American Journal of Tropical Medicine and Hygiene 94.6 (2016):1218-1222.
20. LeJohn HB. "Structure and expression of fungal calmodulin gene". Journal of Biological Chemistry 264.32 (1989): 1936619372.

21. De Carvalho MJ., et al. "Functional and genetic characterization of calmodulin from the dimorphic and pathogenic fungus Paracoccidioides brasiliensis". Fungal Genetics and Biology 39.3 (2003): 204-210.

22. Zhang Y., et al. "Phylogeography and evolutionary patterns in Sporothrix spanning more than 14000 human and animal case reports". Persoonia 35 (2015): 1-20.

23. Oliveira MM., et al. "Development and optimization of a new MALDI-TOF protocol for identification of the Sporothrix species complex". Research in Microbiology 16.2 (2015): 102-110.

24. Madrid H., et al. "Sporothrix globosa, a pathogenic fungus with widespread geographical distribution". Revista Iberoamericana de Micología 26.3 (2009): 218-222.

\section{Assets from publication with us}

- Prompt Acknowledgement after receiving the article

- Thorough Double blinded peer review

- Rapid Publication

- Issue of Publication Certificate

- High visibility of your Published work

Website: https://www.actascientific.com/

Submit Article: https://www.actascientific.com/submission.php

Email us: editor@actascientific.com

Contact us: +919182824667 